\title{
Improving polytechnic students' high-order-thinking-skills through inquiry-based learning in mathematics classroom
}

\author{
Muhammad Sani Abdurrahman', Abdullah Abdul Halim², Osman Sharifah ${ }^{3}$ \\ ${ }^{1}$ Department of Mathematics, Waziri Umaru Federal Polytechnic Birnin Kebbi, Nigeria \\ ${ }^{2,3}$ Faculty of Social Sciences and Humanities, School of Education, Universiti Teknologi Malaysia, Malaysia
}

\begin{abstract}
Article Info
Article history:

Received Feb 19, 2021

Revised Jul 2, 2021

Accepted Jul 16, 2021

Keywords:

HOTS

IBL

Mathematics classroom

Polytechnic education

ABSTRACT

Mathematics is one of the most emphasized subjects and has grown immensely to provide a strong base for programs in science, engineering and technology. Training students in this field will give them the opportunity to improve their high order thinking skills (HOTS). But the students' HOTS level is at low stage due to the learning approaches employed in classrooms. As a result, the study aimed at looking into the effect of inquiry-based learning (IBL) in improving polytechnic students' level of HOTS. Quasiexperimental design was used in this study involving two sampled National Diploma II classes. There were 73 students participated in this study (36 students for experimental group and 37 students for control group). HOTS questions and worksheets based on IBL are the instruments used for this study. At the $\alpha=0.05 \quad(p=0.000)$ level of significance, the results of the independent-sample t-test revealed a significant difference between the mean post-test scores of the experimental group and the control group. Moreover, the students' overall HOTS level was discovered to be (applying, analyzing, evaluating, and creating) improving through this approach. In conclusion, IBL can have a positive effect on the HOTS of polytechnic students in mathematics classroom.
\end{abstract}

This is an open access article under the CC BY-SA license.

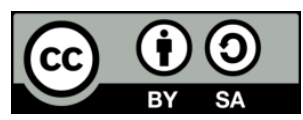

Corresponding Author:

Muhammad Sani Abdurrahman

Department of Mathematics

Waziri Umaru Federal Polytechnic Birnin Kebbi

Birnin Kebbi - Argungu Rd, Birnin Kebbi, Nigeria

Email: abdurrahman@wufpbk.edu.ng

\section{INTRODUCTION}

Among the significant part of the educational system that provides the workforce needed for the industrial and technological growth of a country with middle-level workers is a polytechnic education. The advancement of polytechnic education is of high significance at this time when Nigeria is recovering from an economic recession because it has the potential to be a tool for diversify economy through the development of entrepreneurship in order to minimize unemployment. Jahun [1] stated that polytechnic education is mainly designed to prepare students for technical and vocational professions so that they can become selfemployed after graduation and create employment for others; resulting in the award of National Diplomas, Higher National Diplomas, and Postgraduate Diplomas that are essential to a nation's needs and growth. Nowadays, citizens' educational attainment and quality determines a nation's future, which is why countries with well-educated populations, which characterize the 21 st century in the fields of science, engineering, technology, and social sciences, are the most advantageous [2]. 
Building experiences that engage students, inspire them to develop their problem-solving skills, allow them to think critically as well as to make logical sense of their learned experiences is one of the challenges of teaching mathematics in the 21 st century. It is therefore important to improve the knowledge of mathematics that can compete at both local and international levels so as to produce human capital with $21 \mathrm{st}$ century skills. Nur, et al. [3] and Abdullah, et al. [4] notes that mathematics does not requires only learning the fundamental concepts and skills, but also requires the understanding of application of problem-solving skills, developing mathematical communication and instilling positive values. Students are now challenged to think critically in order to improve their knowledge and learn more concepts in a variety of academic fields by using the available resources at their disposal. Assisting students in learning mathematical thinking has been recognized as an essential educational goal which describe a thinking that is reasoned, goal-oriented, and purposeful [5], [6]. As a result, Schoenfeld [7] pointed out that it is very important for everyone to improve high-order-thinking-skills (HOTS) and should be extended to students in particular because it will encourage them to think creatively, skeptically, and critically about issues that were often encountered in the 21 st century. HOTS may provide relevant life skills for students and provide them with an added value in improving their self-esteem and knowledge of content [8]. In this intensely competitive era of acquiring new knowledge, students are highly encouraged to process and store the acquired new knowledge in long-term memory so as to connect it to prior knowledge, and analyze it to solve real-world problems [9], [10].

Research has shown that students still did not master the revised Bloom Taxonomy of HOTS comprising of application, analysis, evaluation and creation [4]. Noor-Suhaily, et al. [11] note that students find it difficult to apply the knowledge they acquire in the classroom to their everyday lives. The assertion was confirmed by the study of Conklin, et al. [12] and Muhammad, et al. [13], whom stated that students struggle to integrate their prior mathematical knowledge while still using an efficient method to solve a problem. Moreover, students often face difficulties in analyzing information due to their inability to draw conclusions and present facts to back up their claims. According to Conklin, et al. [12], majority of students can comprehend questions, obtain information as well as examine it. Still, it is unfortunate that students' failure to make generalizations or connections between information leads them to making wrong conclusions. This shows that students' ability to solve problems that involve in-depth review remains constrained. Students are said to be lacking in the analysis aspect of HOTS since they are accustomed to the problems in the preceding test which only highlighted the stages of recalling, comprehension, application, and analysis; whereas other studies reported low level of evaluation stage [11]. As a result, students have difficulties in the creation aspect since new and existing knowledge should be implemented, examined and tested to create a solution to a problem [14]. As a result, students face difficulties in making and creating a solution as well as struggle with HOTS levels of applying, analyzing, and evaluating when it comes to problem solving. This indicates that students' HOTS levels are weak and just below the normal standard.

HOTS contributes to student academic achievement Conklin [12]; the learning process includes models, techniques and approaches to learning that can optimize students' learning experiences in HOTS training. Cognitive engagement is critical in making successful classroom activities to build HOTS among students than additional guide activities and textbooks that typically concentrate more on remembering, gathering information and organizing skills [11]. It is now important for every student to have computational skills and basic algorithmic of solving different problems, but this does not mean that they will have HOTS and conceptual knowledge to solve new or non-routine problems [8], [15]. The National Research Council (NRC) and National Council of Teachers of Mathematics (NCTM) considered HOTS as a stimulus for improving future education in mathematics [16], [17]. Mathematics curriculum focusing on HOTS increases the achievement of students, particularly in problem solving skills and critical thinking abilities [18].

Inquiry-based learning (IBL) is a method that focuses on the needs of the students that incorporates their interest and scientific methods of developing thinking skills [19]-[21]. IBL teaching is based on the constructivist framework, where students develop their ideas and concepts, following certain steps under the supervision and guidance of a teacher. The steps begin with activity, whereas the activity leads to concepts; on the other hand, the concepts do not necessarily lead back to the activity [22]. IBL is characterized as the use of questions and formulating problems in order to serve as a catalyst for learning as well as engage students with lifelong learning through observations, collecting data, making judgments and practicing the acquired knowledge [20]. In order to better explain what inquiry is all about, the outlines five main characteristics [23]: "learners must be involved in scientifically oriented questions; they need to respond to the questions raised; they are to provide explanations from the evidence provided; their explanations are to be connected to scientific knowledge; and they are to communicate and justify their proposed explanations." Despite all the advantages of the inquiry method, few pieces of literature documented their activities in Nigerian colleges due to the nature of the curriculum and inadequate knowledge of inquiry practices by teachers [24]-[26]. However, because of the complex nature of education and high demand of technological advances, the exposure of the teacher to different teaching methods is important. 


\section{STATEMENT OF THE PROBLEM}

Mathematics is the basis and bedrock for understanding science, engineering and technological disciplines that are integral part of modern society when combined together. Noor-Suhaily, et al. [11] stated that the HOTS of students in mathematics had not been improved by various teaching methods such as the lecture method used in teaching. This is because students were taught with conventional learning strategy, where exam passes, cookbooks and teacher-centered were the major focus. Studies carried out by different researchers, however, pointed out that students' HOTS level in mathematics is declining as a result of the learning practices used in schools; most students are taught through lower-order thinking skills such as recalling, memorizing and understanding. Consequently, in order to establish strategies and techniques that will focus on successful learning as well as increase HOTS among students in mathematics, systematic and rigorous studies must therefore be carried out.

The Federal Government of Nigeria has made significant investments on providing all the recommended elements that make learning mathematics successful, but it is unfortunate that the performance of students at all levels of education has declined, which is of great concern to stakeholders in education [27], [28]. Research studies have shown that HOTS teaching in Nigerian educational system does not follow a logical path [29], [30], and it is not yet clear on to what extent mathematics teachers use inquiry-based learning to enhance students HOTS, even though HOTS are among the dominant thinking skills required in the 21 st century. Therefore, this research was conducted to improve students' HOTS through inquiry-based learning in mathematics classrooms.

The research objectives are: 1) To determine the effect of IBL on polytechnic students' academic performance in mathematics classroom; 2) To evaluate the effectiveness of IBL in improving polytechnic students' HOTS in mathematics classroom. From the research objectives, the following questions were raised: 1) What is the effect of IBL on polytechnic students' academic performance in mathematics classroom? 2) What is the effectiveness of IBL in improving polytechnic students' each level of HOTS (applying, analyzing, evaluating, and creating) in mathematics classroom?

\section{RESEARCH METHOD}

In this study, a quantitative approach was employed. A quasi-experimental design was used to test the effectiveness of the IBL strategy using two groups (experimental and control) as the research samples were randomly distributed [31]. In this type of design, the groups were observed and analysed before and after being exposed to a treatment [32].

This study took place in a polytechnic, targeting all National Diploma II (ND II) students offering the course of linear algebra (MTH 213). Three colleges of the institution were purposively selected [31], [33], [34] for the study. The reason for the selection is that the NDI students have had the basic prerequisite knowledge of linear algebra course (logic and linear algebra, MTH 111); and all the students also offer linear algebra as a compulsory course in their first, second and third years. Therefore, using simple balloting methods, two ND II classes are randomly selected as the study samples from the three collages of the institution. In addition, a hat-draw was used to assign experimental and control groups to the selected classes. The total number of students involved in this study was 73 (36 and 37 for both experimental and control groups respectively). This number of students is adequate for the collection and analysis of quantitative and qualitative data [33], [34]. Table 1 shows the samples that are selected for the study.

Table 1. Samples selected for the study

\begin{tabular}{ccc}
\hline College & Group & Number of students \\
\hline Engineering programmes & Experimental & 36 \\
Science \& technology programmes & Control & 37 \\
Total number of students & & 73 \\
\hline
\end{tabular}

To determine the level of homogeneity and understanding in the subject area, the two groups were given a pre-test before administering the treatment. The groups were separately instructed, meeting once a week for a minimum of two hours over a period of seven weeks. The experimental group having undergone IBL treatment, while the control group was subjected to conventional method. After the treatment process, a post-test was given to both groups to measure its effectiveness. The following sub-topics are covered during the intervention process: matrices \& determinants; Cramer's rule; Gaussian elimination; eigenvectors; vector spaces; linear transformation. 
A self-developed test based on the above mentioned sub-topics was constructed by the researchers. The answers of the students were verified with a marking scheme that is constructed based on the score specification table [15]. The test questions are designed to prompt the HOTS of students and were drawn from some recommended textbooks from the modules and topics of the ND II curriculum. Five experts were selected for conducting validity tests for the HOTS test content and scoring rubric based on their experience and qualifications in the field of mathematics education. Based on the score specification table, a four-point scoring rubric was developed by the researchers [15]. The researchers used the rubric based on the measures for each score in order to check the students' work accurately and fairly. The worksheet and scoring rubric were subjected to content validity testing by three mathematics education content experts. Adjustments were made based on the experts' feedback prior to being distributed to the actual groups.

Data in this study were collected through pretest and posttest. Analysis of students' scores were measured by comparing the results of the pretest and posttest. In doing the statistical test, the assumptions that need to be evaluated for the accuracy of the test interpretation are the scale of measurement, and the scores should be normally distributed in the population. The result of the pretest and posttest were analyzed statistically using mean, SD and t-test in order to determine the effectiveness of IBL in improving polytechnic students' each level of HOTS. One way to assess the significance of the findings is to compute the effect size, also known as 'strength of association'. This statistic indicates the relative magnitude for the difference between means [15]. Cohen's d is used to compare groups in terms of standard deviation units.

\section{RESULTS AND FINDING}

In accordance with the rubric, both tests were collected and marked. Data collected from the HOTS test were statistically analyzed at alpha $=0.05$ level of significance using descriptive statistics of mean, standard deviation (SD), and independent sampled t-test.

\subsection{Pre-test}

Both groups were given the same pre-test prior to the intervention process in order to determine their level of homogeneity. Independent sampled t-test statistic is used to confirm whether or not the mean pre-test scores are statistically significant as shown in Table 2. As shown in Table 2, independent sample ttest statistic was used at a significance level of alpha $=0.05$ in comparing the pretest scores of both experimental $(\mathrm{M}=37.96, \mathrm{SD}=4.62)$ and control $(\mathrm{M}=37.81, \mathrm{SD}=3.37)$ groups with a difference in mean of 0.15 . This difference was found to be statistically non-significant at $t(71)=0.196$ and $\mathrm{p}>0.001$. For this test, Cohen's d was 0.04 , which can be described as a very small effect size in the mean difference [35]. To further study the differences of HOTS in the scores of pretests for both experimental and control groups among the students, independent-samples t-test was used to analyze each HOTS as shown in Table 3.

The independent sample t-test statistic was used at a significance level of alpha $=0.05$ to analyze the scores of pretests for both experimental and control groups regarding each HOTS. After pretest, both group students demonstrated low level of HOTS as the outcome of the analysis was not significant in each HOTS. The result for each HOTS from Table 3 illustrates that applying $\mathrm{t}(71)=0.163$ and $\mathrm{p}>0.001$; analyzing $\mathrm{t}(71)=0.144$ and $\mathrm{p}>0.001$; evaluating $\mathrm{t}(71)=0.130$ and $\mathrm{p}>0.001$; and creating $\mathrm{t}(71)=0.117$ and $\mathrm{p}>0.001$.

Table 2. T-test comparison for both experimental and control groups on pre-test

\begin{tabular}{lcccccccc}
\hline \multicolumn{1}{c}{ Group } & $\mathrm{N}$ & $\overline{\mathrm{X}}$ & $\mathrm{SD}$ & $\mathrm{SE}_{\mathrm{M}}$ & $\mathrm{df}$ & $\mathrm{t}$-value & $\mathrm{P}$ & Remark \\
\hline Experimental & 36 & 37.96 & 4.62 & 0.73 & 71 & 0.196 & 0.892 & Not Sig. \\
Control & 37 & 37.81 & 3.37 & 0.49 & & & & \\
\hline
\end{tabular}

Table 3. Independent sampled t-test of the pre-test scores for each HOTS of both experimental and control

\begin{tabular}{ccccccccc}
\multicolumn{10}{c}{ groups } \\
\hline HOTS & Group & $\mathrm{N}$ & $\overline{\mathrm{X}}$ & $\mathrm{SD}$ & $\mathrm{df}$ & t-value & $\mathrm{P}$ & Remark \\
\hline Applying & Experimental & 36 & 8.75 & 1.46 & 71 & 1.160 & 0.163 & Not Sig. \\
& Control & 37 & 9.11 & 1.20 & & & & \\
Analysing & Experimental & 36 & 7.08 & 1.30 & 71 & 0.144 & 0.630 & Not Sig. \\
& Control & 37 & 7.13 & 1.25 & & & & \\
Evaluating & Experimental & 36 & 9.89 & 1.62 & 71 & 0.720 & 0.130 & Not Sig. \\
& Control & 37 & 9.62 & 1.03 & & & & \\
Creating & Experimental & 36 & 9.68 & 1.43 & 71 & 1.021 & 0.117 & Not Sig. \\
& Control & 37 & 8.91 & 1.23 & & & & \\
\hline
\end{tabular}




\subsection{Post-test}

After the intervention process, all groups were given the same post test to see the effect of the intervention. Independent sampled t-test statistic is used to confirm whether or not the mean post-test scores are statistically significant as shown in Table 4 . Table 4 shows independent sample t-test statistic was used at a significance level of alpha $=0.05$ in comparing the posttest scores of both experimental $(M=55.46, S D=3.97)$ and control $(\mathrm{M}=43.32, \mathrm{SD}=4.97)$ groups with a difference in mean of 12.14. This difference was found to be statistically significant at $\mathrm{t}(71)=12.640$ and $\mathrm{p}<0.001$. For this test, Cohen's $\mathrm{d}$ was 2.70 , which can be described as a large effect size in the mean difference [35]. To further study the differences of HOTS in the scores of posttest for both experimental and control groups among the students, independent-samples t-test was used to analyze each HOTS as shown in Table 5.

Table 4. T-test comparison for both groups on post-test

\begin{tabular}{lcccccccc}
\hline Group & $\mathrm{N}$ & $\overline{\mathrm{X}}$ & $\mathrm{SD}$ & $\mathrm{SE}_{\mathrm{M}}$ & $\mathrm{df}$ & $\mathrm{t}$-value & $\mathrm{P}$ & Remark \\
\hline Experimental & 36 & 55.46 & 3.97 & 0.85 & 71 & 12.640 & 0.000 & Sig. \\
Control & 37 & 43.32 & 4.97 & 0.98 & & & & \\
\hline
\end{tabular}

Table 5. Independent sampled t-test of the post-test scores for each HOTS of both experimental and control

\begin{tabular}{ccccccccc}
\multicolumn{10}{c}{ groups } \\
\hline HOTS & Group & $\mathrm{N}$ & $\overline{\mathrm{X}}$ & $\mathrm{SD}$ & $\mathrm{df}$ & $\mathrm{t}$-value & $\mathrm{P}$ & Remark \\
\hline Applying & Experimental & 36 & 15.60 & 1.54 & 71 & 8.030 & 0.000 & Sig. \\
& Control & 37 & 9.62 & 1.32 & & & & \\
Analysing & Experimental & 36 & 11.01 & 1.03 & 71 & 11.554 & 0.000 & Sig. \\
& Control & 37 & 7.41 & 1.15 & & & & \\
Evaluating & Experimental & 36 & 12.10 & 1.19 & 71 & 15.370 & 0.000 & Sig. \\
& Control & 37 & 10.05 & 1.30 & & & & \\
Creating & Experimental & 36 & 10.56 & 1.31 & 71 & 12.046 & 0.000 & Sig. \\
& Control & 37 & 7.62 & 1.44 & & & & \\
\hline
\end{tabular}

For applying skills, Table 5 indicates that the mean scores of the posttest for both experimental and control groups are $(M=15.60, S . D=1.54)$ and $(M=9.62, S . D=1.32)$ respectively with a difference in mean of 5.98. This difference was found to be statistically significant at $\mathrm{t}(71)=8.030$, and $\mathrm{p}<0.001$. For this test, Cohen's d was 4.16, which can be described as a large effect size in the mean difference [35]. As for analyzing skills, Table 5 shows the mean scores of the posttest for both experimental and control groups to be $(\mathrm{M}=11.01, \mathrm{~S} . \mathrm{D}=1.03)$ and $(\mathrm{M}=7.41, \mathrm{~S} . \mathrm{D}=1.15)$ respectively with a difference in mean of 3.6 . This difference at $\mathrm{t}(71)=11.554$, and $\mathrm{p}<0.001$ was found to be statistically significant. The Cohen's $\mathrm{d}$ for this test was 3.30, which in mean difference can be described as a large effect size [35].

Regarding evaluating skills, Table 5 indicates that the mean scores of the posttest for both experimental and control groups are $(M=12.10, S . D=1.19)$ and $(M=10.05, S . D=1.30)$ respectively with a difference in mean of 2.05 . This difference was found to be statistically significant at $t(71)=15.370$, and $\mathrm{p}<0.001$. For this test, Cohen's d was 1.65 , which can be described as a large effect size in the mean difference [35]. Finally, creating skills also shows a significant differences (sig. value $=0.000$ ) in Table 5 between the mean scores of the posttest for both experimental and control groups $(M=10.56, S . D=1.31)$ and $(\mathrm{M}=7.62, \mathrm{~S} . \mathrm{D}=1.44)$ respectively, with a difference in mean of 2.94 . This difference at $\mathrm{t}(71)=12.046$, and $\mathrm{p}<0.01$ was found to be statistically significant. The Cohen's $\mathrm{d}$ for this test was 2.14 , which in mean difference can be described as a large effect size [35].

\section{DISCUSSION}

The inquiry-based learning (IBL) learning strategy was found to have a significant effect on students' high order thinking skills (HOTS) based on the findings of the independent sampled t-test. The result indicates that the level of HOTS of the experimental group is greater that the control group. The result showed that learning via IBL significantly improve the HOTS level of students. Through in the use of the IBL, it was discovered that polytechnic students' cognitive skills can be stipulated in enhancing HOTS since students are encouraged to develop their knowledge and explore beyond what the teacher provided. Conklin, et al. [12] and Lee [36] support this argument, indicating that the use of IBL will improve students' HOTS levels. IBL has been found to enhance students' HOTS as a result of students' involvement in making generalizations based on observation and analysis of the examples provided in the worksheet. The statement is supported by previous studies [37]-[39], who argue that HOTS can be stimulated by students through the 
discovery of patterns as they improve their understanding of concept. Overall, this approach can help students improve their conceptual understanding and equip them in using their cognition to its full potential. This means that the students' HOTS is indirectly improved [12], [38], [39].

Based on the findings of independent sampled t-test statistic, the IBL learning technique was discovered to have a significant impact on the skills of application. The result indicates that the experimental group's mean score is higher than the control group's application skills. This is because, after learning through IBL, students can grasp and apply basic mathematical principles in a variety of situations. Using a worksheet that corresponds to an IBL as a learning tool has been found to stimulate the ability of students to the applying skill. According to Rajendran [10] and Aliyu [40], IBL learning strategy allows students to actively participate in observations, identifying trends and drawing conclusions based on the collected information. According to Thompson [39] and Goethals [41], learning concepts of mathematics is vital for fostering HOTS, especially in the application parts, because students can apply what they've learned to solve issues in diverse situations, especially if they've mastered the concept well. The findings of the independent sampled t-test, however, have showed that the IBL learning approach has a significant difference in the analyzing skill. A comparison between the mean scores of posttests indicates that the experimental group reveals a greater enhancement as they can more reliably examine, collect and synthesize information in order to address new questions. This is due to the fact that as part of the IBL approach, they were instructed to conduct an investigation. The students were also taught to look for similarities, differences, and connections between the concepts of mathematics using the worksheet. Goethals [41] and Abdullah [42] notes that by defining relationships between variables, students can receive a clear visualization that will help them better analyze problems. This result indicates that an IBL strategy can stimulate the analyzing skill of students.

In addition, the independent sampled t-test statistical outcome also revealed a significant difference in the evaluating ability of the IBL learning strategy. The result indicates that the mean score for the experimental group for evaluating ability is also higher than that of the control group. This is because the students have gone through IBL strategy in the worksheet. In order to identify trends and thus draw assumptions, this strategy has trained them to fully concentrate on observing several examples given. The emphasis provided supported the cognitive capacity of the students to provide justifications and explanations for their decisions [36]. A significant difference was also found in the results of the independent sampled ttest statistic for the creating of skills. The result, however, indicates that the mean score is higher for the experimental group than that of the control group. This indicates that the result of the IBL strategy has stimulated the cognitive level of students to the highest level, which is creating. Students are taught how to make generalizations after discovering patterns through the use of a worksheet in the IBL learning activity. In the aspect of creating, the tasks allow students to predict and stimulate students' HOTS. The experimental group students are better able to deal with questions that are directly linked to creating aspect than the students in the control group. According to the findings, the IBL approach can facilitate the development and enhancement of HOTS, particularly creating skills. If students are taught how to identify patterns and make discoveries in order to determine relationships, they will be able to make predictions and solve problems [10], [37], [38]. According to Lee [36], when students are regularly exposed to an environment that allows them to develop and predict variables, their cognitive level is indirectly strengthened to the maximum level, which improves their HOTS.

\section{CONCLUSION}

The HOTS of students can be improved by the IBL approach, according to the findings of this study. The results show that through IBL strategy, learning mathematical concepts can stimulate and improve the HOTS of students. This is due to the IBL learning strategy's ability to increase HOTS, evaluate interest, and inspire students to examine mathematical concepts. Students who were confronted with this problem may have paid less attention and exerted less effort in developing and expressing their conclusions. For the experimental group, this condition has caused the mean scores of some HOTS skills to be comparable to that of the control group in their post-test group. The control group appears to be less skilled because they are not forced to think in HOTS because they rely only on their teacher's knowledge, as a result, they are unable to articulate justifications and reasons for their actions.

Nevertheless, previous studies have shown that it is difficult for students to understand certain subjects of mathematics because the concept is too abstract. This can be tackled by introducing the IBL technique, because the approach shows effectiveness in learning mathematical concepts. Furthermore, the usage of IBL will enhance students' cognitive levels and assist them in exploring and making generalizations based on the analysis of various cases provided. As a result, this strategy improves students' knowledge, helps them to make generalizations about a specific relationship, and encourages higher-level thinking. 


\section{ACKNOWLEDGEMENTS}

The authors are grateful for the financial support from the Ministry of Education and Universiti Teknologi Malaysia. UTMShine Grant no. Q.J130000.2413.09G34 was used to fund this research.

\section{REFERENCES}

[1] I. S. Jahun, "The Roles and Contributions of Nigerian Polytechnics in the Development of Surveying and Geoinformatics Education," Issues, Prospects and Challenges: A Global Perspectives. FIG Working Week: Helsinki, Finland, May 29-June, 2017.

[2] B. S. Umar, "A Cognitive Analysis of Problem-Based Learning in Teaching Mathematics at Senior Secondary School Level," Unpublished PhD Thesis, Usmanu Danfodiyo University Sokoto, 2014.

[3] N. L. Z. Abidin, et al., "Thinking blocks: Solving fraction problems involving higher order thinking skills," Man in India, vol. 97, no. 17, pp. 121-132, 2017.

[4] A. H. Abdullah, et al., "Using active learning with smart board to enhance primary school students' higher order thinking skills in data handling," Universal Journal of Educational Research, vol. 8, no. 10, pp. 4421-4432, 2020, doi: 10.13189/ujer.2020.081009.

[5] S. A. Muhammad, et al., "A systematic review on the impact of peer tutoring strategy in linear algebra among polytechnic students," Journal of Critical Review, vol. 6 no. 5, pp. 298-305, 2019 doi: 10.31838/jcr.07.06.52.

[6] S. A. Muhammad, et al., "Developing mathematical thinking among polytechnic students in linear algebra through peer tutoring strategy", Journal of Advanced Research in Dynamical and Control Systems, vol. 12, no. 3, pp. 423-434, 2020, doi: 10.5373/JARDCS/V12I3/20201210.

[7] A. Schoenfeld, How We Think. CA: University of California-Berkeley, 2010.

[8] H. M. Soh, "Using Active Learning With Smart Board to Enhance Primary School Students' Higher Order Thinking Skills in Data Handling," PhD Thesis, Universiti Teknologi Malaysia, 2019.

[9] R. Collins, "Skills for the $21^{\text {st }}$ century: Teaching higher-order thinking", Curriculum \& Leadership journal, vol. 12, no. 14, pp. 48-56, 2014.

[10] N. Rajendran, Teaching and Acquiring Higher-Order Thinking Skills: Theory \& Practice. Malaysia: Universiti Pendidikan Sultan Idris, 2008.

[11] M. Noor-Suhaily, et al., "Enhancing students' higher-order thinking skills (HOTS) through an inductive reasoning strategy using geogebra," International Journal of Emerging Technologies in Learning, vol. 15, no. 3, pp. 156-179, 2020, doi: 10.3991/ijet.v15i03.9839.

[12] W. Conklin, Higher Order Thinking Skills to Develop 21st Century Learners. Huntington Beach, CA: Shell Education Publishing, Inc., 2012.

[13] S. A. Muhammad, et al., "Polytechnic students' mathematical thinking processes in linear algebra: A qualitative approach," Universal Journal of Educational Research, vol. 8, no. 9, pp. 3946-3957, 2020, doi: 10.13189/ujer.2020.080919.

[14] S. R. Hassan, R. Rosli, and E. Zakaria "The use of i-Think map and questioning to promote higher-order thinking skills in mathematics," Creative Education, vol. 7, no. 7, pp. 1069-1078, 2016, doi: 10.4236/ce.2016.77111.

[15] S. M. Brookhart, How to Assess Higher-Order Thinking Skills in Your Classroom. Alexandria, Virginia USA: ASCD, 2010.

[16] National Council of Teachers of Mathematics, Principles and Standards for School Mathematics. NCTM, Reston, Virginia, 2000.

[17] National Research Council (NRC), Adding It Up: Helping Children Learn Mathematics, J. Kilpatrick, J. Swafford, and B. Findell, Eds., National Academy Press, Washington, D.C., 2001.

[18] K. Devlin, Mathematics Education for a New Era: Video Games as a Medium for Learning. Natick, Massachusetts: A K Peters, Ltd., 2011.

[19] B. A. Crawford, "Moving the Essence of Inquiry into the Classroom: Engaging Teachers and Students in Authentic Science," Issues and Challenges in Science Education Research, vol. 12, no. 1, pp. 580-588, 2012.

[20] J. S. Lederman, et al., "Meaningful assessment of learners' understanding about scientific inquiry: The views about scientific inquiry (VASI) questionnaire," Journal of Research in Science Teaching, vol. 51, no. 1, pp. 65-83, 2014.

[21] A. V. Mudau, "Teaching difficulties from interactions and discourse in a science classroom," Journal of Educational and Social Research, vol. 3, no. 3, pp. 113-120, 2013.

[22] K. S. Taber, "Constructivism as Educational Theory: Contingency in Learning, and Optimally," in J. Hassaskhah, ed., Educational Theory. Nova Science Publishers, 2011, pp. 118-121.

[23] Nigeria Research and Development Council (NERDC), "Workshop on Difficult Mathematical Concepts Report," Nigerian Educational Research and Development Council, Lagos, 2005.

[24] N. Akben, "Improving Science Process Skills in Science \& Technology Course Activities, Using the Inquiry Method," Education \& Science, vol. 40, pp. 111-132, 2015, doi: 10.15390/EB.2015.4266.

[25] S. Bakir, "Critical Thinking Dispositions of Pre-Service Teachers," Educational Research and Reviews, vol. 10, no. 2, pp. 225-233, 2015.

[26] I. A. Ojediran, et al., "Impact of laboratory-based instructional intervention on the learning outcomes of low performing senior secondary students in physics," Creative Education, vol. 5, no. 4, pp. 97-206, 2014.

[27] B. O. Ogunleye, et al., "Everyday Phenomenon in Mathematics Education: Impact on Male and Female Students' Achievement, Attitude and Practical Skills in Urban and Pre-Urban Settings in Nigeria," Pakistan Journal of Social Sciences, vol. 8, no. 6, pp. 316-324, 2011. 
[28] A. S. Okedeyi, T. O. Ogunmade, A. M. Oginni, and S. B. Durojaiye, "Nigeria Science Teachers' Perceptions of Effective Science Teaching and their Classroom Teaching Practices in Junior Secondary Schools in Lagos State, Nigeria," Journal of Education and Practice, vol. 4, no. 25, pp. 78-86, 2013.

[29] A. Aboluwodi, "Imperative of teaching critical thinking in higher institutions in Nigeria," Journal of Teaching and Teacher Education, vol. 4, no. 1, pp. 11-15, 2016.

[30] S. B. Adeyemi, "Developing Critical Thinking Skills in Students: A Mandate for Higher Education in Nigeria," European Journal of Educational Research, vol. 1, no. 2, pp. 155-161, 2012.

[31] T. L. White and D. McBurney, Research Methods. Belmont, CA: Wadsworth, Cen-Gage Learning, 2010.

[32] M. A. Sani, Introduction to research methodology and statistics: a guide for students and supervisors. Zaria: Ahmadu Bello University Press, 2017.

[33] J. Nieuwenhuis, "Qualitative Research Design and Data Gathering Technique," In K. Maree, Ed., First Steps in Research. Pretoria: Van Schaik's Publishers, 2013, pp. 70-98.

[34] J. Seabi, "Research Designs and Data Collection Techniques," In K. Maree, Ed., Complete Your Thesis or Dissertation Successfully: Practical Guidelines. Cape Town: Juta and Company Ltd., 2012, pp. 81-95.

[35] L. Cohen, L. Manion, and K. Morrison, Research Methods in Education, 8th Ed. New York, USA: Routledge, Taylor \& Francis Group, 2017.

[36] S. M. Lee, "The Relationships between Higher Order Thinking Skills, Cognitive Density, and Social Presence in Online Learning," Internet and Higher Education, vol. 21, no. 1, pp. 41-52, 2014.

[37] F. J. King, L. Goodson, and F. Rohani, "Higher Order Thinking Skills: Definitions, Strategies, and Assessment," Educational Services Program 2010.

[38] N. Nourdad, S. Masoudi, and P. Rahimali "The effect of higher order thinking skill instruction on EFL reading ability," International Journal of Applied Linguistics and English Literature, vol. 7, no. 3, pp. 231-237, 2018, doi: 10.7575/aiac.ijalel.v.7n.3p.231.

[39] T. Thompson, "Mathematics Teachers' Interpretation of Higher-Order Thinking in Bloom's Taxonomy," International Electronic Journal of Mathematics Education, vol. 3, no. 2, pp. 96-109, 2008.

[40] B. Aliyu, "Critical Thinking Skills and Teaching Conceptions of Nigerian Physics Teachers in Inquiry-Based Learning Classrooms," An Unpublished PhD Thesis, Universiti Teknologi Malaysia, 2020.

[41] P. L. Goethals, "The Pursuit of Higher-Order Thinking in the Mathematics Classroom: A Review," United States Military Academy, West Point, NY, 2013.

[42] A. H. Abdullah, B. Shin, and M. S. Abdurrahman "A comparative study of mathematics assessment practices between Malaysian and South Korean secondary schools mathematics teachers," Universal Journal of Educational Research, vol. 8, no. 11, pp. 5015-5035, 2020. 